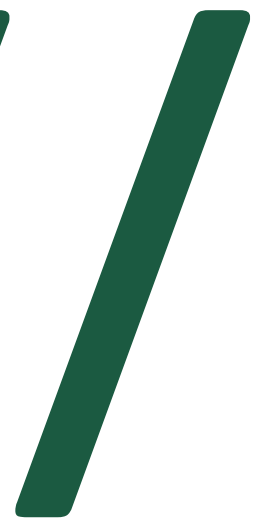

\title{
A reinvenção intermidiática do cinema
}

The intermedial

reinvention

of cinema

\section{Cecília Mello}

${ }^{1}$ Professora Associada no Departamento de Cinema, Rádio e Televisão da Escola de Comunicações e Artes da Universidade de São Paulo (ECAUSP). Autora de The cinema of Jia Zhangke: realism and memory in Chinese film (Londres: Bloomsbury 2019 - Honourable Mention - Best Monograph 2020 - British Association of Film, Television and Screen Studies).E-mail: cecilia.mello@usp.br 
Resumo: O livro de Ágnes Pethő Cinema and intermediality: the passion for the in-between encara a questão da intermidialidade no cinema com surpreendente profundidade e erudição e, como tal, ilumina e abre novos caminhos na teoria do cinema e da mídia.

Palavras-chave: teoria do cinema; intermidialidade; remediação; metalepse.

Abstract: Ágnes Pethö's book Cinema and intermediality: the passion for the in-between faces the question of intermediality in the cinema with astonishing depth and erudition, and as such it enlightens and opens new paths in film and media theory.

Keywords: film theory; intermediality; remediation; metalepsis. 
Cinema and intermediality: the passion for the in-between é mais do que um trabalho de amor, é um trabalho de paixão. O livro de Ágnes Pethő encara a questão da intermidialidade no cinema com surpreendente profundidade e erudição e, como tal, ilumina e abre novos caminhos na teoria do cinema e da mídia. A apresentação em capa dura, preta e lustrosa é muito bonita, com uma colagem de imagens e textos que a enfeitam parcialmente e atraem o leitor com uma combinação paradoxal de superfícies em mise-en-abyme. Esta é a imensurável contribuição da autora para a área, o resultado de anos de pesquisa advinda de Cluj-Napoca na Romênia que, aos poucos, mas convincentemente, abriu o universo do cinema - e o universo dos estudos de cinema - pelo prisma da intermidialidade. Como diz Serge Daney na epígrafe cuidadosamente escolhida para o livro, "a paixão é excessiva, ela quer o cinema, mas também quer que o cinema se transforme em algo mais". E é a paixão de Pethő pelo intermediário, o que também significa uma rara combinação de teorização e análise, que efetivamente envolve filmes individuais e, às vezes, obras inteiras nesse "algo mais", repetidamente.

Esta é a segunda iteração do livro. Ele apareceu pela primeira vez em 2011 com a Cambridge Scholars Publishing, e sua força inovadora agora é recanalizada em uma edição ampliada que inclui revisões, reescritas, três novos capítulos e um índice onomástico. Pethő é Professora de Estudos Cinematográficos na Universidade Húngara Sapientia da Transilvânia, além de editora da revista de acesso aberto em língua inglesa, Acta Universitatis Sapientiae: Film and Media Studies. De 2011 a 2020, as ideias apresentadas na primeira edição do livro foram ajustadas e reavaliadas, com a ajuda de uma série de eventos na Romênia e no exterior dedicados à intermidialidade e ao cinema. Tive o prazer de participar de um congresso em Cluj em 2016 intitulado The Real and the Intermidial, no qual pesquisas de alto nível foram apresentadas e debatidas a partir de uma chamada para trabalhos altamente original, que muitas vezes desejei até mesmo citar em meus escritos! Esses eventos resultaram em um diálogo envolvente com acadêmicos internacionais de todo o mundo, entre os quais Lúcia Nagib, da Universidade de Reading, no Reino Unido, que assina o prefácio da segunda edição e cuja admiração pelo trabalho de Pethő transparece em suas próprias ideias sobre intermidialidade. Além disso, as conferências, edições especiais de revistas e outras publicações apresentadas em um período relativamente curto revelam a força intelectual de Pethő e sua disposição generosa, e não é de admirar que ela tenha construído uma comunidade de pesquisadores que gravitam ao seu redor, transformando a Romênia e Cluj em um centro no atual mapa de estudos sobre intermidialidade. 
A preocupação teórica central do livro é levantar e testar diferentes hipóteses sobre o emparelhamento dos dois termos, cinema e intermidialidade. Apesar da modesta descrição da autora sobre suas intenções e realizações, o livro oferece não apenas um relato abrangente da teoria de intermidialidade até agora, mas também propõe novas metodologias e análises originais que, como Nagib aponta em seu prefácio, "reescrevem toda a história do cinema, reconcebendo os paradigmas clássicos, modernos, pré e pós-cinematográficos à luz da intermidialidade”. Acredito que a grande força do livro está na capacidade de oferecer uma contribuição decisiva tanto para a teoria da mídia e do cinema quanto para a história do cinema, sempre movida pela paixão da autora pelo cinema e pelas artes visuais e pelo seu restabelecido compromisso com as próprias obras de arte, abertas por novas leituras que criam e recriam constelações novas e mutáveis.

Intermidialidade é um conceito altamente maleável que tem sido cada vez mais utilizado nas últimas duas décadas, em grande parte devido à introdução e disseminação da tecnologia digital e a consequente multiplicação das interações midiáticas. Pethő o entende como as interconexões e interferências que acontecem entre as diferentes mídias, focando em suas relações e não em suas estruturas. Há um parti pris que pode parecer um tanto prescritivo se confrontado com a enormidade de possibilidades oferecidas pelos estudos intermidiais, qual seja, a escolha deliberada de Pethő em falar sobre cinema, entendido como um tipo de filme destinado a ser exibido em uma tela grande e em uma sala escura. Essa circunscrição de seu escopo de pesquisa, entretanto, é justamente o que fornece a profundidade de sua sondagem teórica e histórica. Essa ancoragem é necessária: o cinema torna-se a plataforma de lançamento a partir da qual essas expedições ao mundo do intermediário terão início e à qual retornarão, pois o interesse está nas figurações intermidiais dentro de um filme.

O livro é dividido em quatro partes e abrange a maleabilidade dos estudos da intermidialidade, evitando uma abordagem teleológica. A primeira parte, intitulada Cinema in-between media, é composta por quatro capítulos que oferecem uma visão geral da intermidialidade como teoria, conceito e método. O primeiro capítulo é composto como uma historiografia de metodologias que pode, a princípio, parecer um tanto assustadora em suas muitas bifurcações e trifurcações. Mas junte-a com o novo capítulo 2 sobre paradigmas emergentes na teorização da intermidialidade cinematográfica e o leitor tem em suas mãos um extraordinário roteiro para metodologias intermidiais, ao qual retornará muitas vezes. As principais possibilidades abertas pela abordagem intermidial são estabelecidas em um movimento que vai 
de um foco nas fronteiras entre diferentes mídias e diferentes formas de arte até abordagens transmidiáticas em que essas fronteiras se tornam cada vez mais confusas. A única ressalva aqui é que a autora deixou de revisar a referência deste capítulo a Elegy for Theory de David Rodowick, originalmente uma palestra pública feita em 2006, mas que saiu em forma de livro em 2014. Mas o cerne das proposições de Rodowick é abordado, e seu pesar pela perda da teoria do cinema que poderia parecer em desacordo com o apelo de Bordwell e Carroll por "teorização fragmentada" é, na verdade, colocado ao lado das atuais abordagens cognitivas, ecológicas e filosóficas da teoria do cinema, e em oposição ao debate sobre mídia e cinema, incluindo questões de intermidialidade. Essa "fenda" localizada por Pethö, que poderia muito bem ter a ver com "as linguagens do discurso" (inglês versus alemão e francês), torna-se mais complexa com o acréscimo do capítulo 2, onde ela apresenta três novos paradigmas na área que passam de uma abordagem baseada na semiótica para o reino da filosofia do cinema - incluindo a obra de Alain Badiou, Gilles Deleuze, Jacques Rancière e Raymond Bellour e, finalmente, para a equação "o real e o intermidial”. Um dos pontos fortes do livro, portanto, é que ele fornece ao leitor um levantamento geral de definições, abordagens e taxonomias complexas. Também mapeia a intermidialidade e a torna acessível, como conceito, como método e como modo.

Apenas por esses dois primeiros capítulos o livro já merece um lugar de destaque na prateleira mais acessível em sua biblioteca, sempre à mão para ajudar a navegar em um complicado labirinto de metodologias. Mas os capítulos 3 e 4, que complementam a primeira parte intitulada Cinema in-between media, encaram o desafio do livro de frente, interrogando o que a intermidialidade realmente implica em diferentes filmes. A questão impele uma redefinição fenomenológica da intermidialidade que a desloca de uma analogia com a intertextualidade para uma consciência de um espectador corporificado, sensualmente engajado com o filme, e flui para a proposição de dois modos diferentes capazes de gerar um senso de intermidialidade em um filme, o sensual e estrutural. Esta é Peth囚 em sua melhor forma, navegando por espelhos e transfigurações de mise-en-abyme, monumentos arquitetônicos e ruas da cidade por meio de leituras comparativas originais de filmes de Bergman, Kiarostami, Greenaway, Wong Kar Wai, Antonioni (que com razão merece um mini-capítulo dentro um capítulo), Coppola, Godard, Scorsese, Jarmusch, Snow e Tsai Ming-liang. Especialmente atraentes são suas leituras de Shirin (2008) e Persona (1966), filmes que se movem em direção ao mito de um cinema "total", constantemente redefinido por uma consciência elevada da própria natureza sensorial e corporificada do cinema. E no Capítulo 4 o próprio mundo se 
torna um labirinto de mídia, onde "portais sensuais e estruturais de intermidialidade" são encontrados na imagem cinematográfica. Apesar de uma adesão persistente à noção de transparência e ilusionismo que perpassa este capítulo, a intermidialidade dá nova vida aos estudos sobre a cidade cinematográfica, um espaço que ganha vida no livro como um ambiente líquido e háptico onde o flâneur parece flutuar em vez de caminhar, um palimpsesto de imagens compostas como uma poética do enquadramento, e um mundo fragmentado ou justaposto onde a intermidialidade realiza saltos metalépticos entre o imediato e o mediado, entre o figurado e o corporal, entre o pensamento abstrato e a matéria sensorial. Como observou Quintiliano, a metalepse é por natureza uma etapa intermediária, um meio-termo que permite uma passagem para o que é expresso metaforicamente. Em filmes de Tsai Mingliang, Jim Jarmusch e Abbas Kiarostami, Pethő vê a metalepse não como um apelo à decodificação, mas como um convite a uma abordagem contemplativa.

O livro passa então para uma poética histórica do cinema ao enfrentar dois gigantes, Hitchcock e Godard, do ponto de vista de suas figurações intermidiais. O fato de Hitchcock estar localizado na junção do cinema clássico e moderno, e Godard na junção do modernismo e pós-modernismo, como Pethő aponta em sua introdução à segunda edição, logo se torna menos relevante quando entendido em relação à intermidialidade. Em Hitchcock, a pintura é o elemento intermediário que complica os paradigmas nítidos da narrativa clássica e que puxa seus filmes para um mistério sempre presente, não localizado no reino narrativo, pronto para ser resolvido, mas da ordem do inexplicável, assombrando a imagem como dimensão inatingível. Como a sofisticada prosa de Pethő articula, "parece que para Hitchcock, a pintura age como um 'demônio intermidial da imagem cinematográfica', uma doppelgänger midial que está pronto para assumir o comando a qualquer momento, ameaçando perturbar a ordem sensata (e discursiva) do mundo".

Se a pintura evoca um demônio e nos joga no coração do abismo com Hitchcock, o cinema de Godard é visto como "possuído" pelas outras artes e, portanto, ocupa o centro do palco como o paradigma artístico mais importante, ou um dos mais importantes, na intermidialidade cinematográfica. Pethő recorre à decisiva definição de Bolter e Grusin de remediação como o processo que informa a genealogia da mídia ao longo da história e a associa à "ansiedade de influência" de Harold Bloom para localizar o que ela chama de "ansiedade de remediação" no Godard inicial. Aqui, ela vê seu cinema como uma homenagem e como um rival da literatura, seu "parente" mais velho e mais respeitado no mundo das artes. O livro então se aprofunda na exploração de Godard das interconexões entre palavras e imagens, e o proclama um 
cineasta ecfrástico por excelência, sendo sua Histoire(s) du cinéma (1988-1998) o ponto culminante de seu impulso ecfrástico. A intermidialidade ecfrástica de Godard torna-se mais do que um artifício retórico e opera entre diferentes artes, iluminando seus aspectos e realçando sua forma original. A impressão esotérica dessa descrição precipitada faz muito pouca justiça à proposição complexa apresentada por Pethö, que vê quatro tipos diferentes de intermidialidade ecfrástica em Godard, operando com efeitos diferentes.

A parte final do livro investiga o paradoxo de um cinema intermidial de imediação, explorando colagens fotográficas no cinema de José Luís Guerín e Agnès Varda e, nos dois últimos capítulos, dois exemplos notáveis do cinema romeno, Glissando, de Mircea Daneliuc, de 1984, e Sieranevada, de Cristi Puiu, de 2016. Seria difícil eleger a contribuição mais importante deste livro ou mesmo sua seção mais completa, mas a ousada evocação do real em estudos intermidiais na quarta parte certamente a torna uma forte candidata. Esta abordagem tem sido altamente inspiradora e libertadora para mim, informando minha leitura do cinema de Jia Zhangke (Mello, 2019), cuja poética compreendi a partir do ponto de vista da combinação de realismo e intermidialidade.

Em sua vasta reinvenção, Pethő é aqui capaz de tecer intermidialidade na indicialidade do filme e em suas especificidades culturais e ideológicas. Ela o faz ao adotar a dimensão sensual da intermidialidade, que efetivamente elimina o paradoxo que assombra o par entre hipermidialidade e imediação, apontando o ponteiro para a realidade contemporânea em toda a sua complexidade. No primeiro capítulo da quarta parte, o livro altamente reflexivo e ensaístico de Agnès Varda, Os catadores e eu (Les glaneurs et la glaneuse, 2000), convida a uma comparação frutífera com a obra de José Luis Guerín, especialmente seus filmes interconectados Na cidade de Sylvia (En la ciudad de Sylvia, 2007) e Algumas fotos feitas na cidade de Sylvia (Unas fotos en la ciudad de Sylvia, 2007). Mas então Varda recebe seu próprio capítulo, dedicado a um cinema "definido como um artifício entre duas camadas do real: a realidade de si mesma, o mundo pessoal da autora-narradora, e a realidade capturada pela cinematografia no estilo cinéma vérité". As mudanças entre essas diferentes realidades ocorrem por meio de saltos metalépticos, passando de filme em filme, entre realidade e ficção e, finalmente, do figurado para o corpóreo.

O livro termina com dois capítulos que abordam a política da intermidialidade no cinema do Leste Europeu, com foco em Glissando de Daneliuc (1984) e Sieranevada de Puiu. O primeiro diz respeito à história de um apostador inveterado que vê sua vida se desfazendo e descarrilando para a psicose e o suicídio. 
Este estado mental é transmitido por meio de simbolismos intermediários que Pethő lê como uma figuração da vida mental dos romenos durante os anos finais do regime totalitário de Nicolae Ceaușescu. Finalmente, o Novo Cinema Romeno, uma das ondas cinematográficas mais excitantes a surgir no século XXI, é abordado por meio de uma leitura paralela de Sieranevada de Puiu (2016) e a exposição fotográfica homônima. Evocando a "dupla hélice da imagem" de Raymond Bellour, Pethő então propõe um terceiro modelo capaz de criar um sentido de intermidialidade no cinema, que ela chama de "modo expansivo", designando filmes que na verdade se expandem para além dos limites da tela em direção a outras obras de arte interrelacionadas.

Uma das características extraordinárias deste livro é como ele tece uma análise intermidial prática semelhante à "teorização fragmentada" de Bordwell e Carroll, comprometida com a obra de arte em sua singularidade e pluralidade, com um ímpeto teórico e metodológico incorporado em uma vasta gama de estudos e desenvolvido junto aos próprios filmes. As análises textuais são apoiadas e complementadas por fotografias de filmes cuidadosamente escolhidas, generosamente distribuídas pelos capítulos. Descobri que, por vezes, prestou-se atenção excessiva à imagem em detrimento do som, que o livro de alguma forma negligencia. Mas a verdade é que as deficiências deste livro são quase nulas. Ele mostra como o cinema é, e sempre será, o meio de arte que não pode ser contido por categorias e fórmulas únicas. Ele está, como disse André Bazin, ainda por ser inventado. A obra destemida de Pethő mostra-nos que é justamente por isso que o cinema existe em um movimento constante de expansão intrínseca intermidial. Ela faz com que nos apaixonemos pelo intermediário, um território onde o nosso amor pelo cinema pode sempre se renovar.

\section{Referências}

PETHÖ, Á. Cinema and intermidiality: the passion for the in-between. 2. ed. Newcastle upon Tyne: Cambridge Scholars Publishing, 2020.

submetido em: 26 mai. 2021| aprovado em 26 mai. 2021 